\title{
ROTEIRO GEOLÓGICO PELOS EDIFÍCIOS E MONUMENTOS HISTÓRICOS DO CENTRO DA CIDADE DE SÃO PAULO
}

\author{
ANDRÉ GIANNOTTI STERN ${ }^{1}$, CLAUDIO RICCOMINII,2, GELSON LUÍS FAMBRINI ${ }^{3}$ \& \\ MARLEI ANTONIO CARRARI CHAMANI ${ }^{1}$
}

\begin{abstract}
Resumo Rochas ornamentais têm sido o principal material de construção desde o passado mais remoto. Antigas civilizações empregaram estas rochas na construção de fortalezas, pontes, templos, castelos, palácios, casas e muralhas. Tais monumentos, muitos deles hoje em ruínas, constituem não somente o registro histórico de antigas culturas, mas também são fonte de informações sobre as tecnologias e condições sócio-econômicas do passado. $\mathrm{O}$ uso de rochas na construção apresenta um aspecto prático: são materiais naturais, duráveis, de fácil obtenção e que podem ser trabalhados em formas e dimensões específicas. A escolha é baseada essencialmente no seu aspecto estético (artístico), relevando-se as suas características geológicas, tais como composição química e mineralógica, texturas e estruturas primárias e secundárias, fatores esses condicionantes das propriedades físicas e de fundamental importância para o seu desempenho tecnológico. Neste trabalho é proposto um roteiro geológico que tem como objetivo a observação de rochas ornamentais usadas na construção de monumentos históricos e fachadas de edifícios do centro da Cidade de São Paulo. Ele nos remete ao passado e permite examinar os principais tipos de rochas empregadas no contexto dos diferentes períodos históricos, econômicos e sociais da cidade.
\end{abstract}

Palavras-chave: rochas ornamentais, roteiro geológico, centro da Cidade de São Paulo, edifícios e monumentos históricos.

\begin{abstract}
A GEOLOGICAL WALK AMONG BUILDINGS AND HISTORICAL MONUMENTS OF DOWNTOWN SÃO PAULO. Dimension stone was the main building material since the remote past until recent times. Ancient civilizations used stones in the construction of fortresses, bridges, temples, castles, palaces, houses and walls. Such monuments, many of them in ruins, are not only important record of previous cultures, but also source of information concerning past technology and social and economical conditions. The use of stone in construction has a practical aspect because it is a durable, easy to obtain natural material that can be cut or shaped to a specific size. The choice is basically due to its esthetical (artistic) aspects, overlooking its geological characteristics, such as mineral and chemical composition, texture and primary and secondary structure. All these factors are related to the physical nature of the materials and of great importance to their technological performance. The proposed geological walk, with the observation of dimension stones used in historical monuments and building façades in downtown São Paulo, back us to the past and allows to correlate the main types of rocks with different historical, economical and social periods of the city.
\end{abstract}

Keywords: dimension stone, geological walk, downtown São Paulo, historical buildings and monuments.

INTRODUÇ̃̃O A utilização de rochas em diferentes tipos de construções é um fato notório nas antigas civilizações. Desde a antigüidade as rochas são usadas na construção de fortalezas, pontes, templos, castelos, palácios, casas e muralhas dentre outras obras. Dessa forma, ruínas e construções históricas são preciosas fontes de informações sobre o passado tecnológico, social e econômico destes povos. A rocha, além de ser um testemunho da evolução natural da Terra, torna-se também um importante registro das culturas que nos precederam.

O uso da rocha em edificações envolve um significado prático relacionado à sua facilidade de obtenção e durabilidade. A escolha está intimamente relacionada aos aspectos estéticos (artísticos) das rochas, em detrimento de suas características geológicas, tais como composição mineralógica e química, textura, estruturas primárias e secundárias, fatores estes relacionados à constituição dos materiais e de fundamental importância no seu desempenho tecnológico.

A região central da Cidade de São Paulo apresenta uma grande diversidade de materiais rochosos utilizados em sua construção. Em função de suas cores, composições mineralógicas e texturas peculiares, os diferentes tipos de rochas assinalam períodos determinados de uso mais intenso, em função do contexto histórico, arquitetônico e econômico da cidade.

Este trabalho apresenta um roteiro de visitação ao centro histórico de São Paulo, com enfoque nas rochas e suas características geológicas, utilizadas em construções e monumentos. Pretendeu-se abranger no roteiro edificações e monumentos que representassem uma amostragem diversificada de tipos de rochas. Foram selecionados rochas de diferentes origens (ígneas, sedimentares e metamórficas), incluindo exemplos com enfoques paleontológicos e/ou paleoambientais. Todo o roteiro está localizado nas cercanias das principais estações centrais do Metrô, de modo que o percurso possa ser feito a pé, viabilizando a realização de uma excursão geológica em pleno centro urbano e a baixos custos. $O$ roteiro permite ainda a visita a outros locais de interesse histórico e cultural, além de restaurantes, bares e cafés tradicionais, o que deve despertar a curiosidade e estimular a sua realização por pessoas de diferentes faixas etárias.

ÁREA DO ROTEIRO A área do roteiro está localizada na região central da Cidade de São Paulo, entre as estações Sé, São Bento, Anhangabaú e República do Metropolitano de São Paulo (Metrô), incluindo o denominado "Centro Velho" (Fig. 1). A área, de fácil acesso e locomoção, foi escolhida por abranger um conjunto representativo de edifícios e monumentos históricos, construídos em distintas épocas de nossa história, obras de diferentes arquitetos e engenheiros, nas quais foi empregada uma boa variedade de tipos de rochas.

1 - Instituto de Geociências, Universidade de São Paulo (USP), Rua do Lago 562, São Paulo, SP, CEP 05508-080; Fone: +55-11-30914128; E-mail: andrestern@gmail. com, riccomin@usp.br, marleichamani@ig.com.br

2 - Bolsista de Produtividade em Pesquisa do Conselho Nacional de Desenvolvimento Científico e Tecnológico - CNPq (processo 304649/2005-8)

3 - Departamento de Geologia, Centro de Tecnologia e Geociências, Universidade Federal de Pernambuco (UFPE), Avenida Acadêmico Hélio Ramos s/n, Cidade Universitária, Recife, PE, CEP 50.740-530; E-mail: g_fambrini@yahoo.com 


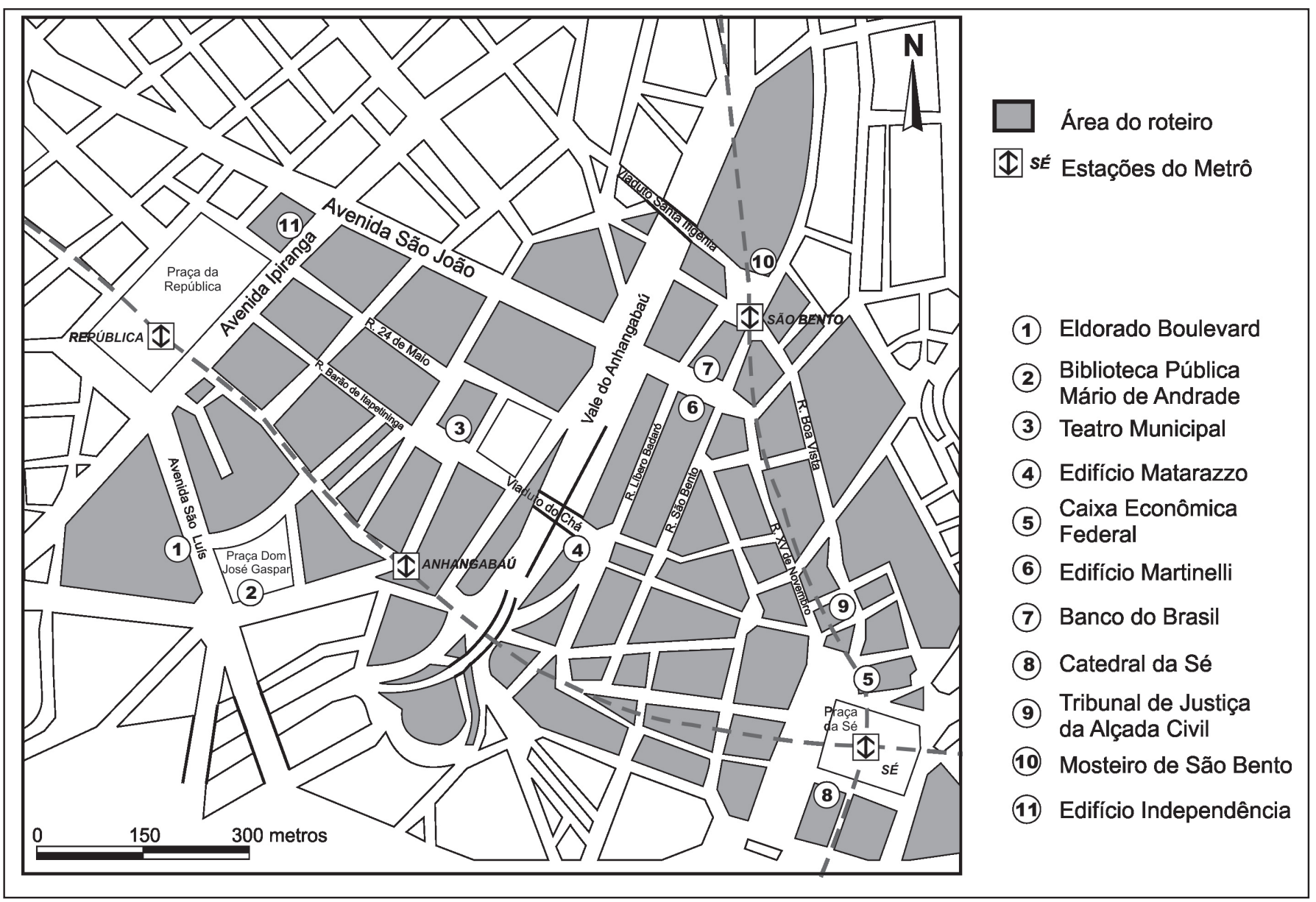

Figura 1. Mapa de localização do roteiro geológico pelos edificios e monumentos históricos da Cidade de São Paulo.

O ROTEIRO GEOLÓGICO Para a seleção dos locais de visita que integram o roteiro realizou-se, inicialmente, uma prospecção de edifícios e monumentos que apresentassem interesse histórico e/ou geológico (Stern et al. 2001). As obras foram documentadas fotograficamente, descritas nos seus aspectos gerais e no tocante às suas características históricas e arquitetônicas. Após serem catalogadas a partir da bibliografia (Azambuja \& Silva 1977, Macedo \& Chieregati 1982, Caruso et al. 1990, JETRO 2000), procurou-se determinar a procedência (pedreiras fornecedoras) das rochas utilizadas em cada obra, com o objetivo de coletar amostras para petrografia. Definidas as procedências (Fig. 2), foram obtidas amostras junto às coleções do Instituto de Geociências da USP ou nas chamadas "marmorarias" da Cidade de São Paulo, que ainda comercializam os mesmos materiais empregados nas obras. Poucos foram os casos em que amostras não puderam ser obtidas e as discussões ficaram restritas aos aspectos macroscópicos observados nas obras.

Finalmente, delineou-se o traçado do roteiro pelas ruas do centro procurando-se incluir obras com diferentes tipos de rochas, de relevante interesse histórico e/ou arquitetônico, situadas em percurso fácil, rápido e viável de ser realizado a pé ou via metrô. O formato do trabalho foi inspirado em obras congêneres sobre o tema, particularmente as de Robinson (1982, 1987, 1988, 1993, 1997), Robinson \& Bishop (1980) e Robinson \& Worssam (1989), nos quais são apresentados roteiros (geological walks) em diferentes locais, desde grandes cidades como Londres, até estudos sobre antigas igrejas construídas no interior da Grã Bretanha, e o de Winkler (1973), importante fonte de informações técnicas sobre a utilização de rochas ornamentais em edifícios e monumentos. Com base nesses critérios, foram se- lecionados 11 locais de interesse: o Hotel Eldorado Boulevard, a Biblioteca Pública Mário de Andrade, o Teatro Municipal de São Paulo, os edifícios Conde Matarazzo, Martinelli, Independência, do Banco do Brasil e da Caixa Econômica Federal, o Tribunal de Justiça da Alçada Civil, a Igreja e Mosteiro de São Bento e a Catedral da Sé (Fig 1).

Hotel Eldorado Boulevard Ianugurado em 1972, o Eldorado Boulevard é um hotel de alto padrão, localizado na Avenida São Luis. Suas colunas externas de entrada são revestidas por sodalita sienito de cor azul, comercialmente conhecido por "Granito Azul Bahia" (Fig. 3). Rocha plutônica alcalina com granulação média, equigranular, o sodalita sienito apresenta notável heterogeneidade composicional, ocorrendo concentrações de feldspatos, sodalita e biotita. A composição mineralógica média compreende sodalita (35\%), plagioclásio $(25-30 \% \%)$, microclínio (15\%), anfíbólio (5\%), biotita (5-15\%) e opacos. É uma rocha de ocorrência restrita, muito apreciada pela sua cor azul. Rochas dessa natureza são exploradas economicamente na Província Alcalina do Sul do Estado da Bahia, com idades neoproterozóicas, variando entre 732 e $676 \mathrm{Ma}$ (Teixeira et al. 1997, Rosa et al. 2005). Nesta província destaca-se o stock de Itaju do Colônia, o corpo mais importantente do ponto de vista econômico (Azambuja \& Silva 1977).

Biblioteca Publica Mário de Andrade Localizado na Praça D. José Gaspar, com entrada principal na Rua Xavier de Toledo, o prédio da Biblioteca Pública Mário de Andrade foi idealizado pelo biblioteconomista Rubens Borba de Morais, inaugurado em 25 de janeiro de 1942 e recebeu o nome do escritor moder- 


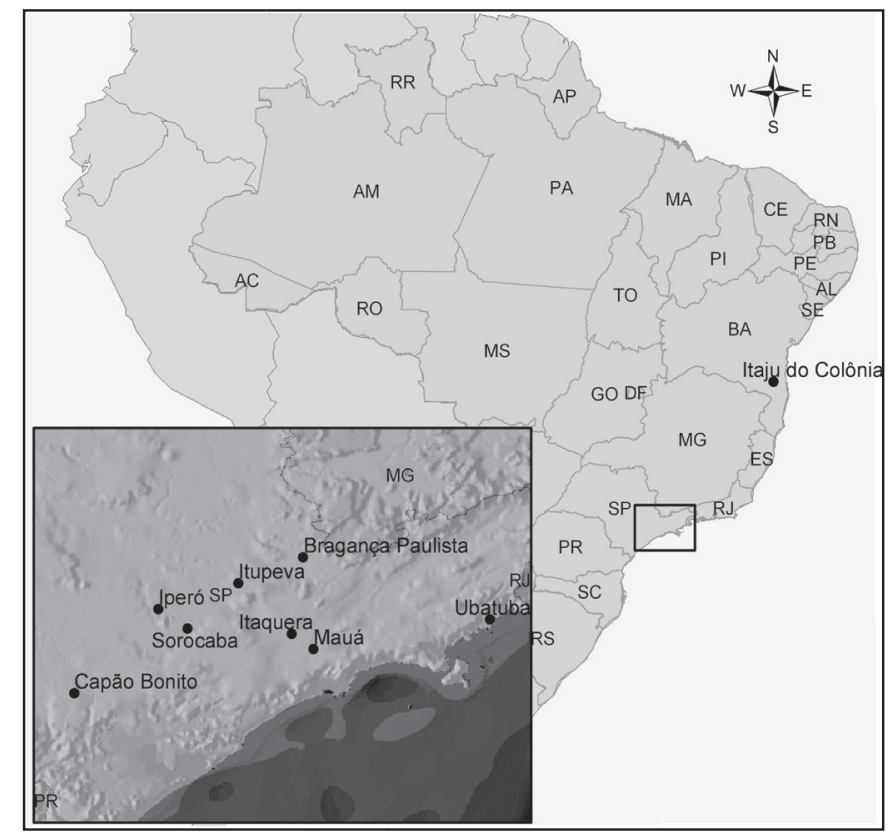

Figura 2. Regiões de procedência da maioria das rochas empregadas em edificios e monumentos históricos da Cidade de São Paulo.

nista em 15 de fevereiro de 1960. A fachada externa de entrada do edifício é revestida por biotita granito porfirítico, comercialmente denominado Granito Cinza Mauá, proveniente das cidades de Mauá e Suzano, SP. É uma rocha plutônica pertencente ao Domínio Embu (Janasi \& Ulbrich 1991), de granulação média, com fenocristais orientados de microclínio. A composição média compreende microclínio (30-34\%) e plagioclásio (25\%), ambos saussuritizados, quartzo (30\%), biotita (15\%) e muscovita $(1 \%)$. Este granito foi largamente utilizado em construções na cidade, tendo como exemplo as estações do Metrô.

Internamente, a biblioteca é revestida por três variedades de rochas importadas, sendo as principais o oficalcito (clorita-tremolita-serpentina-carbonato xisto) e um calcário cinza repleto de fragmentos de fósseis. $\mathrm{O}$ oficalcito é uma rocha metamórfica de baixo grau, milonítica, com fragmentos angulosos, centimétricos a decimétricos de serpentinito e veios carbonáticos (Fig. 4). Tais rochas ocorrem em zonas de subducção da crosta, com a cimentação de detritos ou mesmo de brechas relacionadas às deformações tectônicas de corpos de rochas ultrabásicas. Oficalcitos são comuns nos Alpes e nos Apeninos (Europa). Na Itália são também denominados comercialmente de Verde di Polcevera, Susa, Varalo ou delle Alpi, entre outras designações, variando de acordo com a sua coloração predominante. Há uma variedade translúcida denominada de Onice di Chatillon, oriunda do Val d'Aosta, Itália.

O piso da entrada da Biblioteca Pública Mário de Andrade é revestido com um calcário cinza abundante em fósseis e fragmentos de uma grande diversidade de organismos. Ocorrem conchas de moluscos, algumas delas quebradas, indicando retrabalhamento previamente ao seu soterramento, outras inteiras, sugerindo soterramento dos organismos ainda vivos. Os contornos dos fósseis podem ser observados em todo o piso. Não foi possível a obtenção de amostras para a confecção de seções delgadas e descrições petrográficas, nem estabelecer a proveniência das rochas carbonáticas fossilíferas.

Teatro Municipal de São Paulo Localizado na Praça Ramos de Azevedo, o Teatro Municipal de São Paulo foi construído entre 1907 e 1911, segundo o projeto de Domiziano Rossi e
Cláudio Rossi, e executado pelo escritório de arquitetura Ramos de Azevedo. É revestido, na sua fachada principal, por arenito do Grupo Itararé (Arenito Itararé), rocha sedimentar de origem glacial e idade permocarbonífera, depositada na Bacia do Paraná, que ainda preserva suas estruturas sedimentares. Procedente da região de Araçoiaba, São Paulo, esse arenito é um material adequado para utilização em cantaria pois apresenta forte coesão entre seus grãos devida à cimentação hidrotermal por sílica relacionada à intrusão alcalina do Maciço de Ipanema (Fig. 5).

A outra rocha utilizada na fachada é um biotita granito de coloração cinza claro, com granulação fina e leve orientação marcada pelas placas de biotita. Na sua composição a rocha inclui quartzo (35\%), feldspato $(40 \%)$, biotita $(10 \%)$, muscovita (10\%), anfibólio (5\%). Embora saiba-se que este granito é proveniente de uma antiga pedreira na região de Itaquera, SP, sua localização exata não foi determinada, razão pela qual esta rocha não foi descrita microscopicamente.

Edifício Conde Matarazzo O Edifício Conde Matarazzo (Fig. 6) localiza-se no Viaduto do Chá, esquina com a Rua Doutor Falcão Filho. Atual sede da Prefeitura do Município de São Paulo, foi um dos primeiros edifícios a serem erguidos no Vale do Anhangabaú, após a construção do atual Viaduto do Chá, por volta de 1939. O prédio é revestido externamente por mármore com abundantes estruturas biogênicas tubulares (prováveis tubos de vermes, Fig. 6A) e laminadas (prováveis estromatólitos gerados por algas e/ou cianobactérias, Fig. 6B). Embora provavelmente italiano, não foi possível a determinação precisa de sua procedência.

Edifício Martinelli O Edifício Martinelli foi construído entre 1922 e 1930 por Giuseppe Martinelli (Secretaria Municipal de Planejamento 1984), simboliza o esforço e o poder da criatividade do imigrante italiano no Brasil. Ocupa o quarteirão da Avenida São João, entre as ruas São Bento e Líbero Badaró. Seu andar térreo é revestido inteiramente por granito vermelho róseo, equigranular, de granulação média a grossa e composto por microclínio (35-40\%), quartzo (30\%), hornblenda (5\%), plagioclásio (20\%), minerais máficos (5\%) (Fig 7). Este granito é raramente porfirítico e ocorre no interior e proximidades do Batólito Três Córregos, no sul do Estado de São Paulo, em especial na sua parte oriental, onde constitui a Suíte Capão Bonito (Janasi \& Ulbrich 1985), de idade neoproterozóica (Chieregati et al. 2003). Comercialmente é denominado de Granito Vermelho Capão Bonito (Caruso et al. 1990).

Edifício do Banco do Brasil O Edifício do Banco do Brasil localiza-se na esquina da Avenida São João com a Rua Líbero Badaró. A sua fachada é ornamentada com charnoquito, de idade neoproterozóica (aproximadamente 560 Ma, segundo Janasi \& Ulbrich 1991), que ocorre na faixa litorânea que se estende desde cerca de $17 \mathrm{~km}$ a leste de Caraguatatuba, no Estado de São Paulo, até próximo à divisa com o Estado do Rio de Janeiro (Janasi \& Ulbrich 1985). Apresenta cor verde escuro peculiar, granulação grossa, com megacristais de feldspato com cerca de $3 \mathrm{~cm}$ de comprimento médio. É composto de feldspato potássico $(25 \%)$, plagioclásio como fenocristais $(35 \%)$, quartzo azul esverdeado (15\%), hiperstênio (10\%) e biotita (15\%) (Fig. 8). É empregado no edifício tanto na forma bruta como polida, ao longo do quarteirão da Avenida São João entre as ruas Libero Badaró e São Bento. Comercialmente, é denominado de Granito Verde Ubatuba, embora atualmente não seja mais extraído desta região do litoral norte de São Paulo, mas de outros estados, como Espírito Santo e Minas Gerais, que apresentam ocorrências de natureza semelhante. 
Catedral da Sé Localizada na Praça da Sé, a catedral é o marco zero da Cidade de São Paulo e serve como ponto de referência para atos populares. Sua construção foi iniciada em 1913, sendo inaugurada durante as comemorações do quarto Centená-

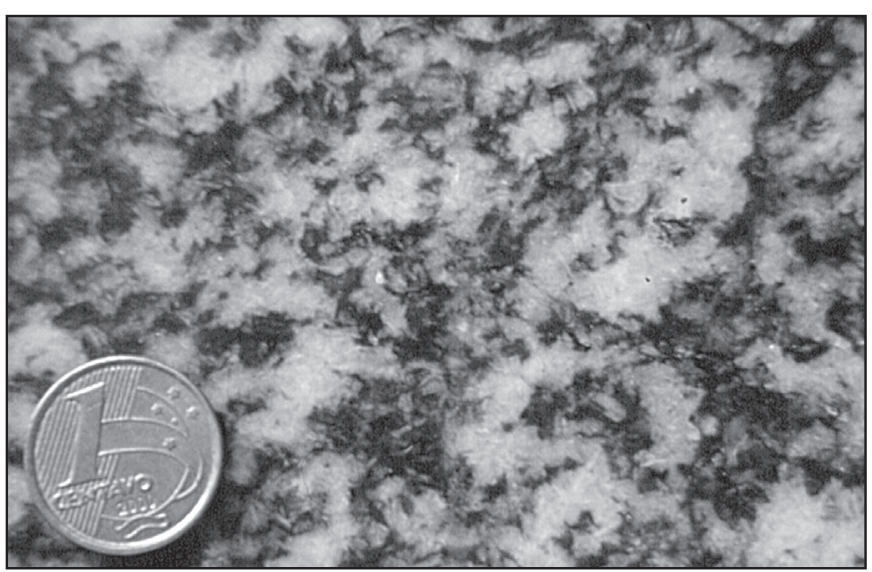

Figura 3. Visão macroscópica do sodalita sienito (Granito Azul Bahia), do sul da Bahia, da fachada externa do Hotel Eldorado Boulevard, Avenida São Luís.

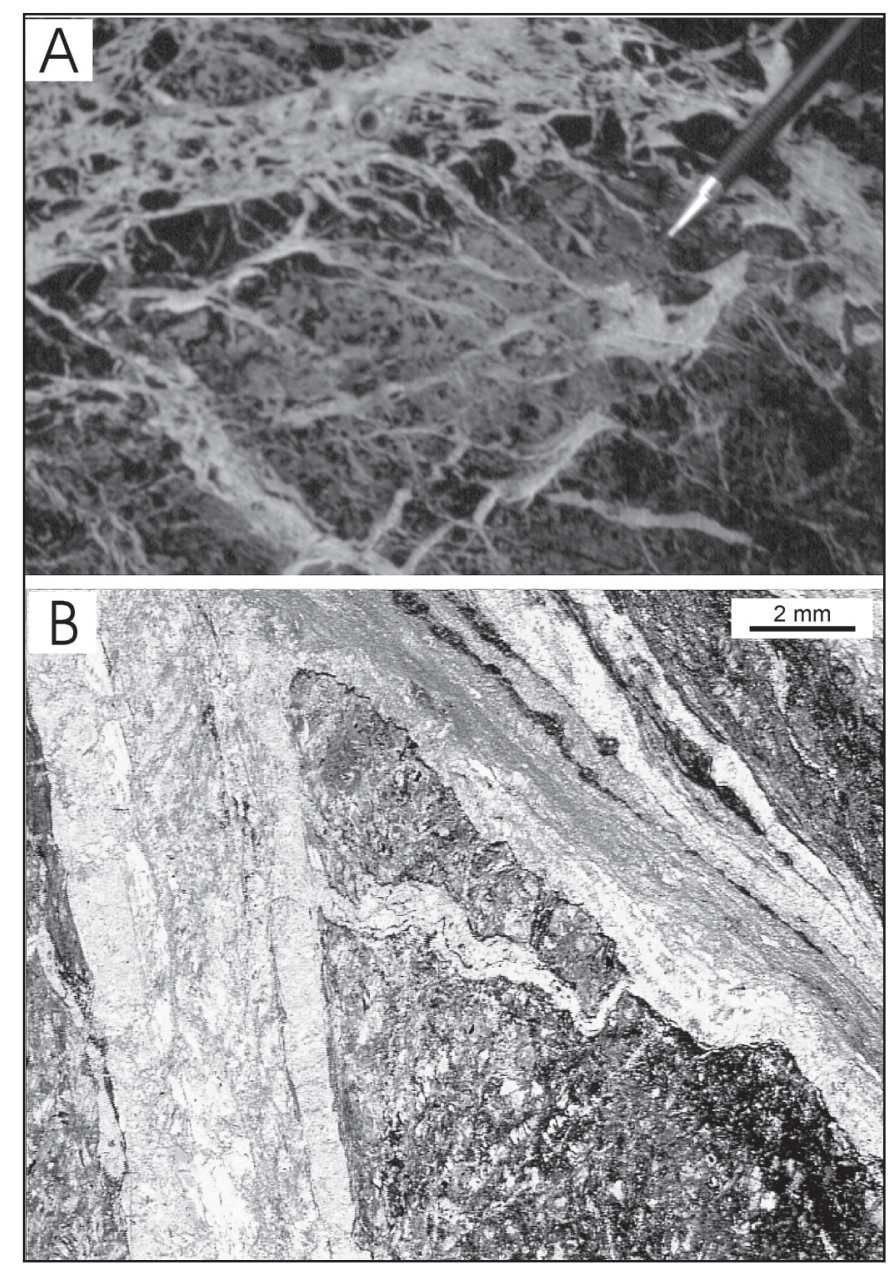

Figura 4. A - Oficalcito da fachada de um prédio da Rua Aurora, defronte ao Teatro Odeon, identico ao utilizado na Biblioteca Pública Mário de Andrade; B - vista da rocha em seção delgada sob luz polarizada, destacando-se a faixa clara dobrada de calcita e a parte escura serpentinítica. rio da Cidade da São Paulo, em 1954, ainda sem as torres, que só foram concluídas em 1970. Recentemente foi restaurada.

A sua estrutura foi construída em biotita monzogranito porfirítico, comercialmente denominado de Granito Cinza Sorocaba (Azambuja \& Silva 1977). É uma rocha de coloração cinza claro, com granulação média, contendo fenocristais de feldspato (com até $2 \mathrm{~cm}$ ) e macroscopicamente composta de quartzo (45\%), feldspato (40\%), anfibólio e/ou biotita (15\%) (Fig. 9). Esta rocha pertence ao Domínio São Roque, do Neoproterozóico, que inclui rochas granitóides aflorantes no seu extremo oeste, nas regiões de Sorocaba e São Francisco, SP (Janasi \& Ulbrich 1985). Este granito é normalmente encontrado com cor rosa e raramente com coloração cinza claro (Azambuja \& Silva 1977).

Caixa Econômica Federal O Edifício da Caixa Econômica Federal (Fig. 10) localiza-se nas proximidades da Praça da Sé. Atualmente é um centro cultural, com andar térreo suntuoso, que se destaca pelas grandes colunas jônicas esculpidas em rocha comercialmente denominada de Granito Preto Piracaia. Trata-se de um monzonito, pertencente ao maciço intermediário de Piracaia, de idade neoproterozóica, proveniente da Cidade de Bragança Paulista, SP (Janasi \& Ulbrich 1991). Apresenta cor verde escuro, com granulação fina e matriz muito fina; é composto de microclínio $(25 \%)$, plagioclásio $(25 \%)$, hornblenda $(20 \%)$, piroxênio $(5 \%)$, biotita $(15 \%)$, titanita $(10 \%)$ e opacos.

Tribunal de Justiça da Alçada Civil O edifício do Tribunal de Justiça, localizado no Pátio do Colégio, apresenta estilo arquitetônico conceitualmente indefinido, mas de composição híbrida e elaborada. Utiliza motivos clássicos, como colunas dóricas na entrada, e elementos ornamentais com provável inspiração maia (Secretaria Municipal de Planejamento 1984).

As colunas frontais são de granito rosa proveniente de Itupeva, SP, que integra o Complexo Granitóide Itu, de idade neoproterozóica (Galembeck 1997). Petrograficamente pode ser classificado como granito, de granulação média, com fenocristais de feldspato potássico com cerca de $2 \mathrm{~cm}$ de eixo maior, às vezes apresentando textura tipo rapakivi (Fig. 11). É composto de microclínio (aproximadamente 40\%), plagioclásio (25-30\%) e quartzo (25-30\%) com pequena proporção de minerais máficos (anfibólio e biotita). Comercialmente é denominado de Granito Rosa Itupeva, com largo uso em construções.

Mosteiro e Igreja de São Bento A atual Abadia de Nossa Senhora da Assunção, localizada no Largo de São Bento, substitui um conjunto arquitetônico que já havia sido reedificado quatro vezes no mesmo local, datando a sua última reconstrução da segunda metade do século dezoito. Em 1907, inicia-se a reconstrução do mosteiro, projeto elaborado pelo arquiteto alemão Richard Bernd, que aliava reminiscências românicas, bizantinas e da arquitetura quatrocentista italiana (identificados pelo uso do arco pleno) rejuvenescidas por meio de pormenores neogóticos (Secretaria Municipal de Planejamento 1984). Externamente, o monastério é revestido por dois tipos de granito. O primeiro é o Granito Rosa Itupeva, semelhante ao utilizado no Tribunal de Justiça da Alçada Civil, diferenciando-se deste pela ausência de textura tipo rapakivi e pela maior proporção de anfibólio, o que permite supor que seja oriundo de uma porção diferente do mesmo corpo. O segundo tipo de rocha empregado é o Granito Itaquera, similar ao utilizado no Teatro Municipal, diferenciando-se por apresentar porções com concentração de minerais máficos, como a biotita

Edifício Independência O Edifício Independência é um prédio de escritórios, localizado à Avenida Ipiranga, 795. Embora não se destaque pelo aspecto externo, internamente é revestido 

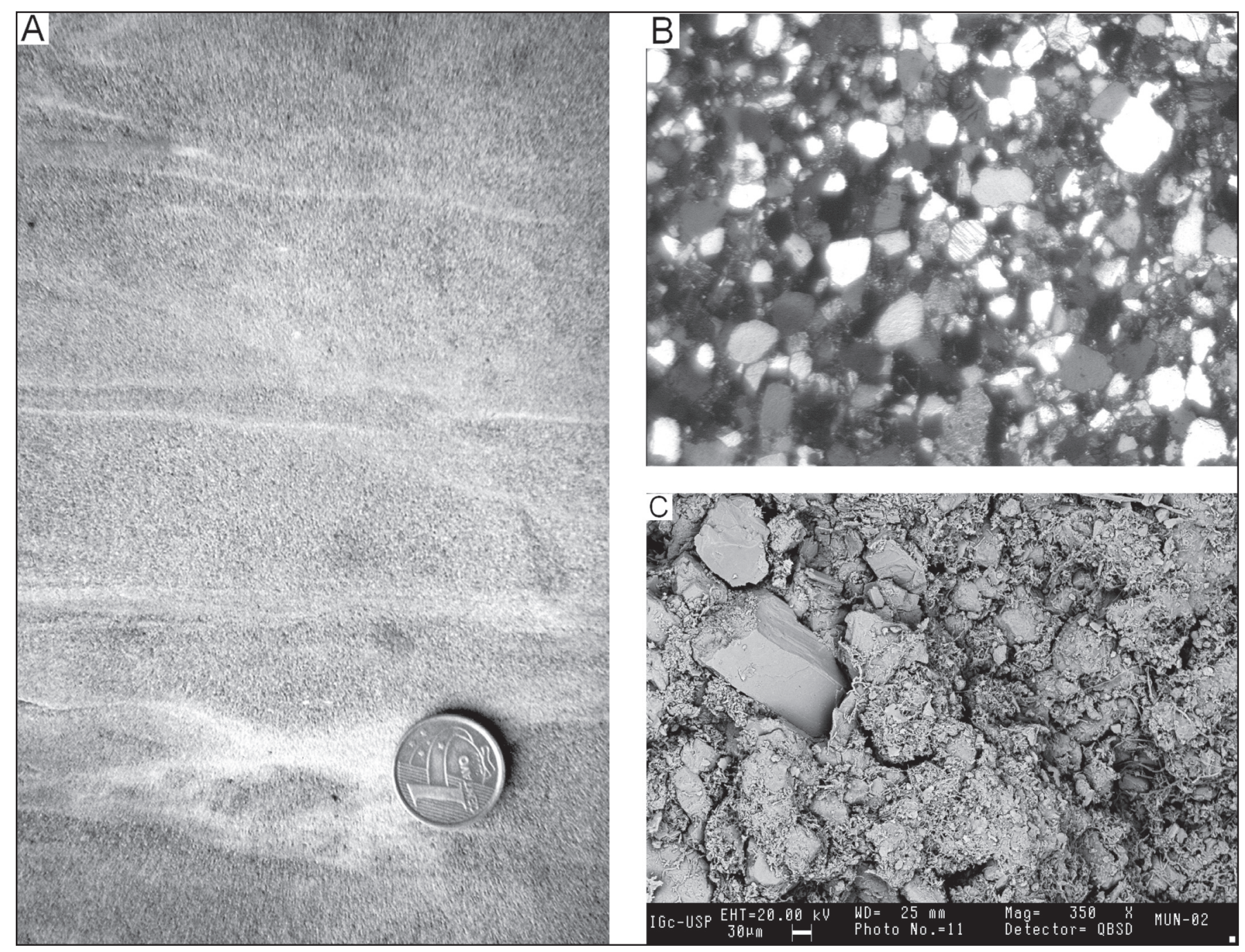

Figura 5. Arenito com cimento silicoso, utilizado no revestimento da fachada do Teatro Municipal de São Paulo: A - aspecto macroscópico da rocha da fachada, mostrando acamamento paralelo; B. seção delgada da mesma rocha, mostrando o formato subangular a subarredondado dos grãos, a textura da rocha e a composição mineralógica, com quartzo predominante; C. imagem da mesma rocha obtida ao microscópio eletrônico de varredura, mostrando a forma e tamanho dos grãos e a presença de argila nos espaços entre os grãos. Notar ainda a presença de material particulado recobrindo os grãos, provável resultado da exposição da rocha à poluição atmosférica.

por rocha carbonática de coloração bege, com inúmeros fósseis em destaque. As observações feitas no local permitiram caracterizar esta rocha como uma coquina carbonática, na qual podem ser observados inúmeros fragmentos de fósseis dispostos de maneira caótica (Fig. 12). São em sua maioria bivalves, denominados rudistas. Estes animais, semelhantes aos encontrados na Biblioteca Pública Mário de Andrade, ocorrem em rochas carbonáticas do Cretáceo e são utilizados como fósseis-índice. Trata-se de um calcário de origem incerta, provavelmente da Itália, e foi encontrada em outros edifícios, também na região central da cidade.

CONSIDERAÇÕES FINAIS A elaboração de um roteiro geológico pelo centro da Cidade de São Paulo é uma contribuição para a melhor divulgação das Geociências junto ao público, turistas e em escolas de ensino fundamental e médio do país.

$\mathrm{O}$ roteiro geológico aqui proposto permite a observação e familiarização com alguns dos tipos de rochas que compõem o nosso planeta. Aborda aspectos como a composição, textura, mineralogia, origem, idade e também para que servem e como são utilizadas essas rochas no nosso cotidiano.
O estudo de rochas ornamentais de monumentos históricos e fachadas de edifícios da Cidade de São Paulo permite traçar uma relação dos principais tipos de rochas utilizados nestas construções em função do período histórico, econômico e social da cidade. $\mathrm{O}$ uso freqüente de mármores e outras rochas carbonáticas européias, provenientes principalmente da Itália, em edifícios e monumentos da segunda metade do século XIX e primeira do século XX, indica forte influência de técnicas e conceitos então em voga na Europa sobre os engenheiros e arquitetos que atuavam na cidade. A partir dos anos 50, com o avanço nas técnicas de exploração e beneficiamento de rochas nacionais, houve o aumento da produção e melhor aceitação no mercado interno de gnaisses, granitos e rochas granitóides, sienitos, dentre outras. Estas modificações se refletem nas construções a partir deste período, onde há predominância de material doméstico com menor uso de rochas importadas, implicando em melhores condições para a conservação e restauro dos monumentos históricos.

A localização na área central da cidade e o enfoque em rochas utilizadas em edificações de interesse histórico e arquitetônico objetivam a integração entre o conhecimento geológi- 


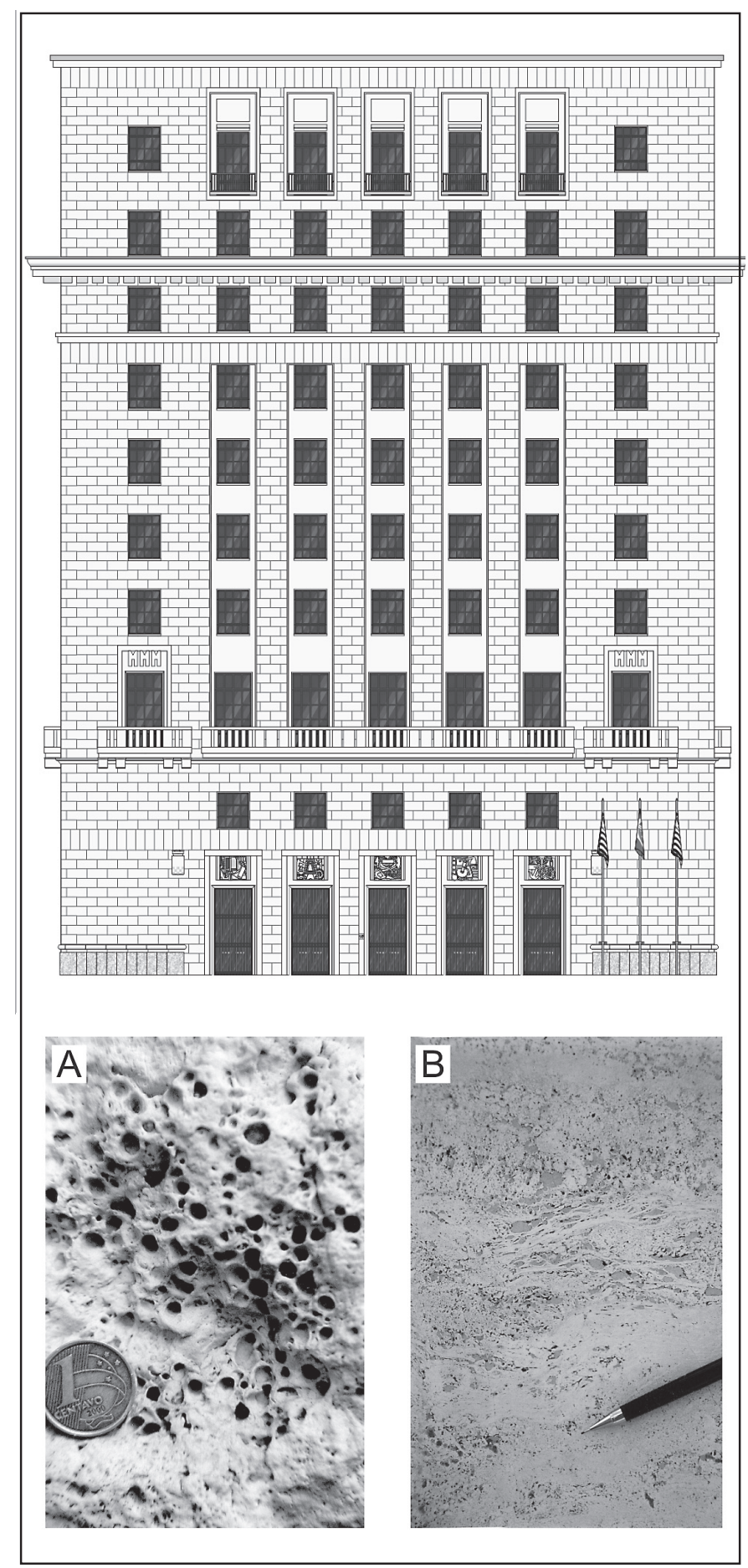

Figura 6. Edificio Conde Matarazzo, Viaduto do Chá: A - aspecto macroscópico do calcário da fachada com estruturas biogênicas tubulares (prováveis tubos de vermes); $B$ - visão macroscópica do calcário da fachada com estruturas biogênicas laminadas, provavelmente geradas por algas elou cianobactérias.

co e outras áreas do conhecimento. Assim, com o auxílio de profissionais de áreas como arquitetura, história, engenharia e geografia, pode-se desenvolver roteiros de estudos com enfoques múltiplos, para pessoas de qualquer faixa etária. Tem-se também a facilidade de acesso à área, permitindo a realização do roteiro com baixo custo.

Outro aspecto a ser destacado é o incremento dos roteiros turísticos em São Paulo, contribuindo com os projetos atuais

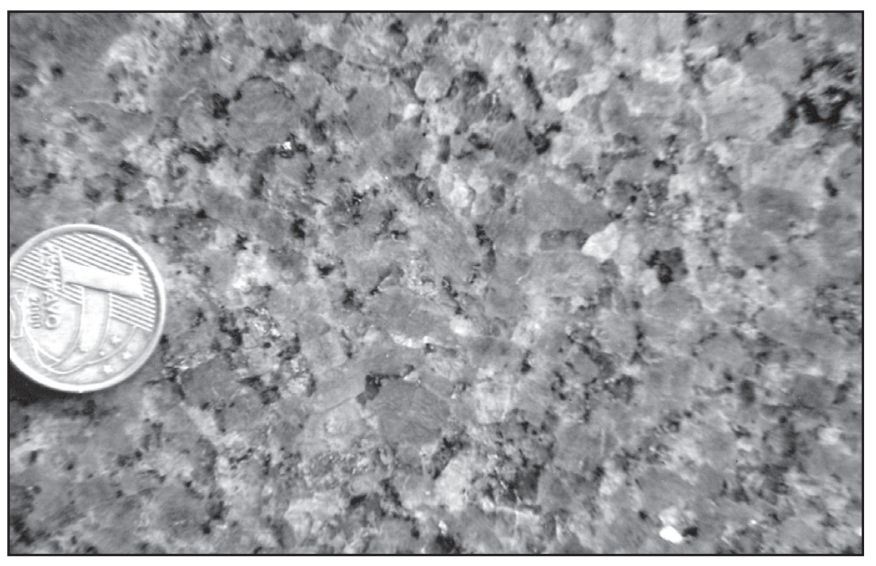

Figura 7. Aspecto macroscópico do Granito da Suite Capão Bonito, Edifício Martinelli, Av. São João.

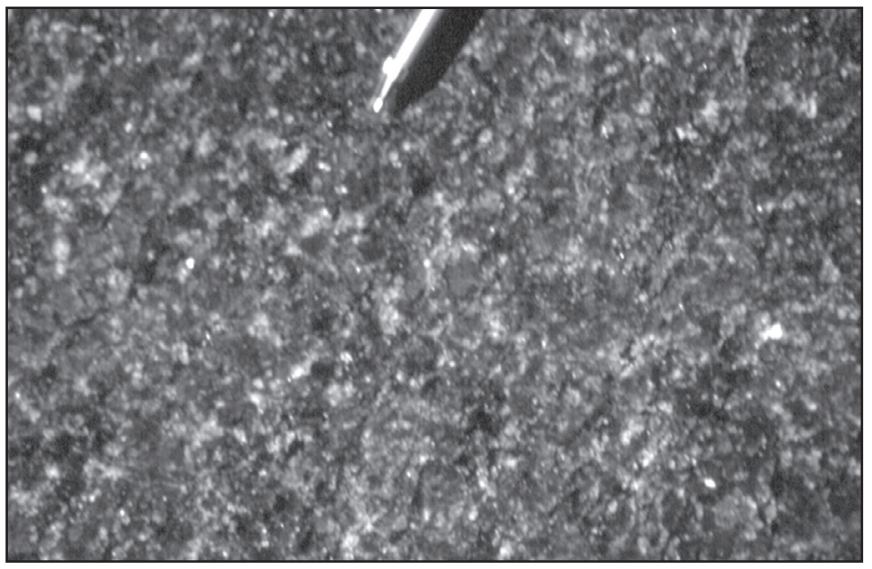

Figura 8. Aspecto macroscópico do charnoquito da fachada do Edifício do Banco do Brasil, Av. São João.

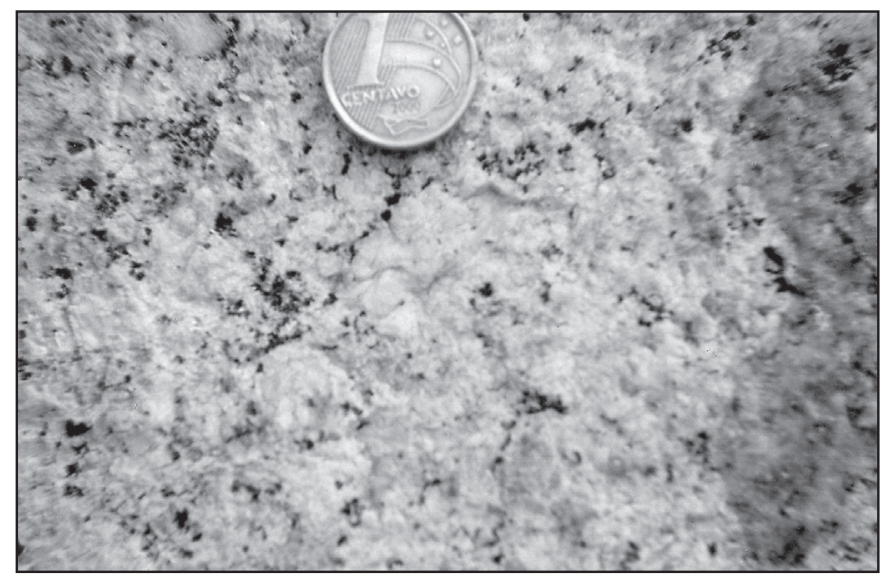

Figura 9. Visão macroscópica do biotita monzogranito porfirítico, Catedral da Sé.

que objetivam a revitalização do centro histórico da cidade.

Agradecimentos Os autores agradecem aos colegas Thomas Rich Fairchild, Sonny Baxter, Johan Hans D. Schorscher e Luis Antonio Chieregati, pelas discussões e sugestões; ao engenheiro Isaac Jamil Sayeg pelo auxílio na microscopia eletrônica de 

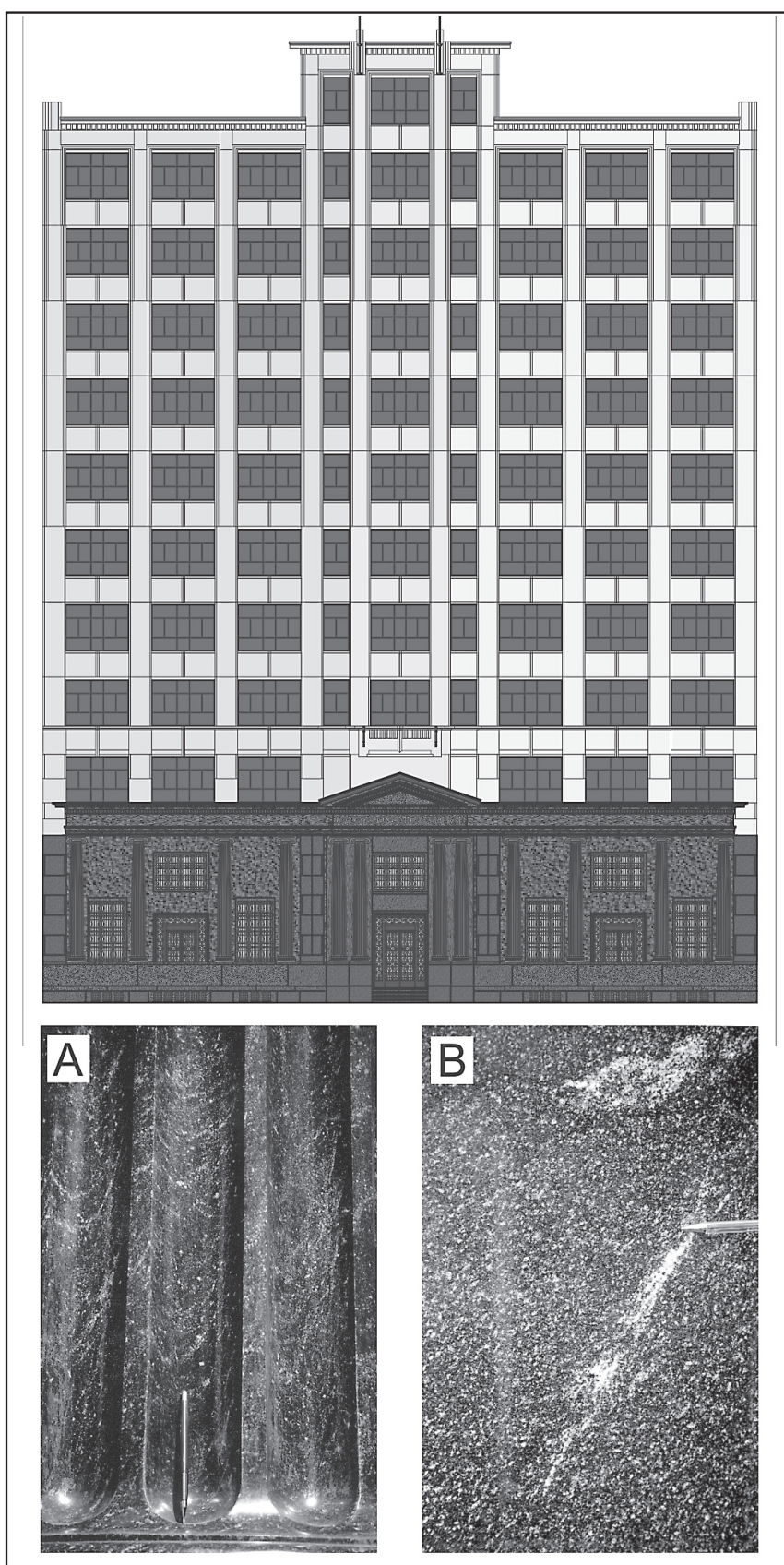

Figura 10. Centro Cultural da Caixa Econômica Federal, proximidades da Praça da Sé: A - detalhe de uma das colunas da entrada esculpidas em monzonito; $B$ - detalhe macroscópico da rocha.

varredura; a Professora Vitoria Regia Peres da Rocha Oliveiros Marciano e a um revisor anônimo da Revista Brasileira de Geociências, pelas sugestões apresentadas durante o processo de revisão do trabalho.

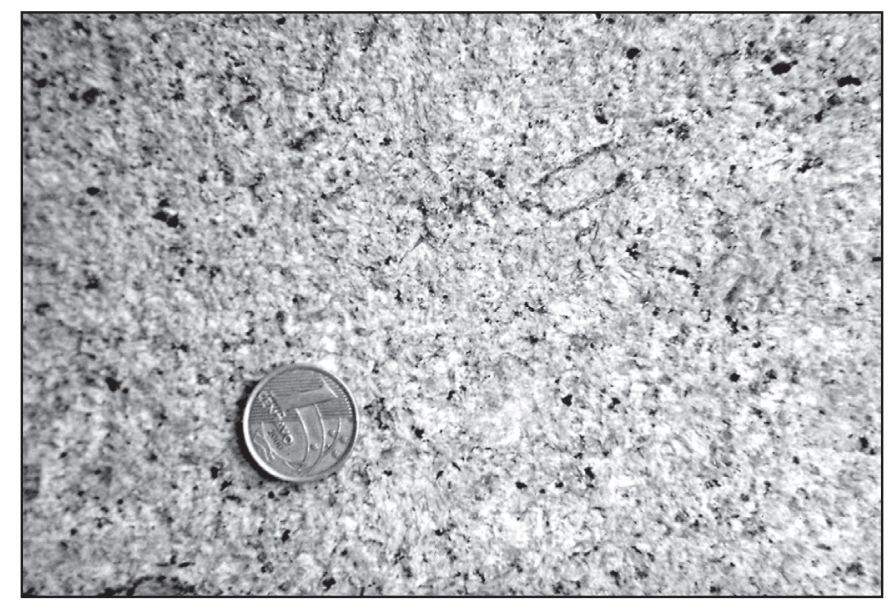

Figura 11. Aspecto macroscópico da estrutura tipo rapakivi do granito das colunas frontais do Tribunal de Justiça da Alçada Civil, Pátio do Colégio.

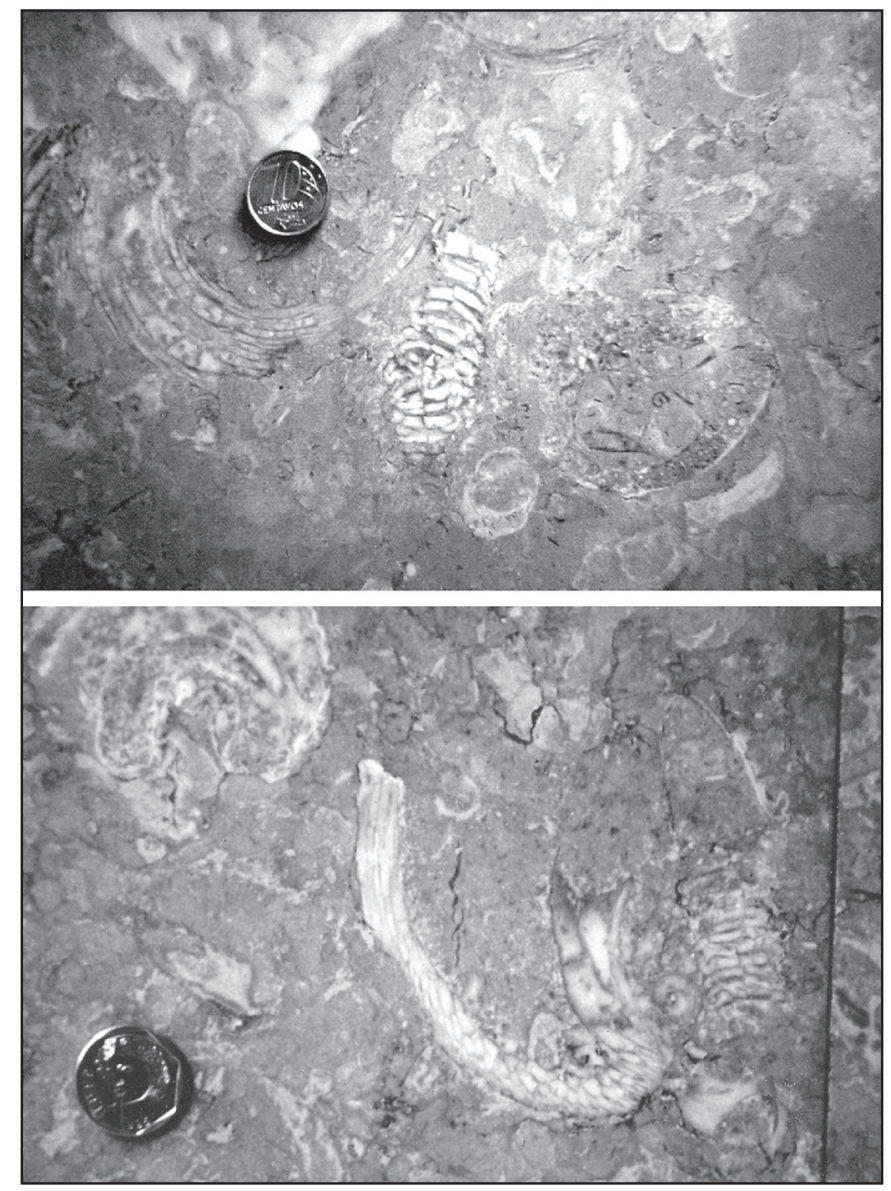

Figura 12. Coquina carbonática, com abundantes fragmentos de rudistas, Edificio Independência, Avenida Ipiranga. 


\section{Referências}

Azambuja J.C. \& Silva Z.C.G. 1977. Perfil analítico dos mármores e granitos. Brasília, Departamento Nacional de Produção Mineral, $64 \mathrm{p}$.

Caruso L.G., Braga T.O., Frascá M.H.O., Farjallat J.E.S., Frazão E.B., Rodrigues E.P., Oliveira M.C. 1990. Catálogo de rochas ornamentais do Estado de São Paulo. Instituto de Pesquisas Tecnológicas do Estado de São Paulo, São Paulo, CD.

Chieregati L.A, Silva S. da, Stern A.G. 2003. Cronoestratigrafia das rochas ornamentais: Informações e conceitos básicos da geologia no marketing e comercialização das rochas ornamentais. In: CETEM/ SBG, Simpósio de Rochas Ornamentais do Nordeste, 4, Fortaleza, Anais, p.46-52.

Galembeck T.M.B. 1997. O completo múltiplo, centrado e plurisserial Itu - SP. Tese de doutoramento, Instituto de Geociências e Ciências Exatas, Universidade Estadual Paulista, Rio Claro, 374p.

Janasi V.A. \& Ulbrich H.H.G.J. 1985. Avaliação das informações disponíveis para os granitóides do Estado de São Paulo. In: SBG/Núcleo São Paulo, Simpósio Regional de Geologia, 5, São Paulo, Anais, p.135-146.

Janasi V.A. \& Ulbrich H.H.G.J. 1991. Late Proterozoic granitoid magmatism in the state of São Paulo, southern Brazil. Precambrian Research, 51:351-354.

JETRO - Japan External Trade Organization. 2000. Catalog of Brazilian stone for construction. Tokyo, Trade Development Department, 91p.

Macedo A.B. \& Chieregati L.A. 1982. Projeto Rochas Ornamentais. São Paulo, Governo do Estado de São Paulo, Secretaria de Economia e Planejamento, Superintendência do Desenvolvimento do Litoral Paulista - SUDELPA, Relatório Técnico, 1v.

Robinson E. 1982. A geological walk around the City of London - Royal Exchange to Aldgate. Proceedings of the Geologists Association, 93:225-246.

Robinson E. 1987. A geology of the Albert Memorial and vicinity. Proceedings of the Geologists' Association, 98:19-37.
Robinson E. 1988. A geological walk in Clerkwell, London. Proceedings of the Geologists Association, 99:101-124.

Robinson E. 1993. A geological walk in Southwark. Proceedings of the Geologists Association, 104:285-299.

Robinson E. 1997. Geology in Rochester, Kent, Saturday, 15th February. Proceedings of the Geologists Association, 108:37-328.

Robinson E. \& Bishop C. 1980. Geological walks around St. Paul's. Proceedings of the Geologists Association, 91:241-260.

Robinson E. \& Worssam B.C. 1989. The geology of some Middlesex churches. Proceedings of the Geologists Association, 100:595-603.

Rosa M.L.S., Conceição H., Leal R.C.M., Macambira M.J.B., Galarza M.A., Oliveira E.C., Marinho M.M., Cunha M.P., Rios D.C. 2005. Idade U-Pb da mineralização de sodalita-sienito (Azul Bahia) no stock litchfieldítico Itaju do Colônia, Sul do Estado da Bahia. Revista Brasileira de Geociências, 35:433-436.

Secretaria Municipal de Planejamento (EMPLASA). 1984. Bens Arquitetônicos no Município e na Região Metropolitana de São Paulo. São Paulo, EMPLASA, 496p.

Stern A.G., Riccomini C., Fambrini G.L., Chamani M.A.C. 2001. Geologia aplicada ao estudo e preservação de monumentos e edifícios em rocha na Cidade de São Paulo. In: Simpósio Internacional Ciência e Tecnologia como Cultura e Desenvolvimento, um enfoque histórico. São Paulo, Universidade de São Paulo, Atas, p.1.

Teixeira W., Kamo S.L., Arcanjo J.B.A. 1997. U-Pb zircon and baddeleyte age and tectonic interpretation of the Itabuna alkaline suite, São Francisco Craton, Brazil. Journal of South American Earth Sciences, 10:91-98.

Winkler E.M. 1973. Stone: properties, durability in man's environment. Springer-Verlag, Viena, 34p. 